\title{
Osmium Tetroxide Fixation of Fine Plant Structures for Electron Microscopy
}

\author{
Marcus A. Hairston \\ Department of Biological Sciences, University of Pittsburgh, \\ Pittsburgh, U.S.A.
}

Received January 19, 1956

Introduction

The suitability of certain plant material for cytomorphological studies has necessitated the incorporation of finer fixation techniques. Delicate plant components such as staminate hairs have not heretofore responded well either to osmium tetroxide fixation for paraffin embedding or to osmium tetroxide fixation for methacrylate embedding when excellent structural differentiation is desired during electron microscopy. Chloroplasts of Paramecium and higher plants have been fixed in osmium tetroxide solutions and prepared for electron microscopy (Granick and Porter, 1947 ; Steinman, 1952; Wolken and Palade, 1952). The cells of staminate hairs, however, possess osmostatic vacuoles which when unbalanced may result in collapse of the cell through plasmolysis or water loss. It is desirable that an osmium tetroxide solution, with a minimum of deletorious properties, be compounded to facilitate examination and orientation during electron microscopy.

\section{Materials and methods}

Staminate hairs of Tradescantia paludosa were fixed for two hours in:

1) $1 \%$ or $2 \%$ osmium tetroxide in distilled water at $\mathrm{pH} 6.5,7.0,7.5$, 8.0 , or 9.0 .

2) $1 \%$ or $2 \%$ osmium tetroxide in acetate-veronal buffer at $\mathrm{pH} 6.5$, $7.0,7.5,8.0$ or 9.0 .

3) $1 \%$ or $2 \%$ osmium tetroxide in $0.1 \mathrm{M}, 0.15 \mathrm{M}, 0.2 \mathrm{M}, 0.25$ or $0.3 \mathrm{M}$ sucrose solutions at $\mathrm{pH} 6.5,7.0,7.5,8.0$ or 9.0 .

Subsequent treatment prior to and including embedding was according to the technique of Newman, Borysko and Swerdlow (1949). At each stage of processing and at intermediate stages material was removed for examination under the light microscope.

\section{Results}

Hairs fixed in $1 \%$ or in $2 \%$ osmium tetroxide in distilled water showed blebs even before final processing; those which were completely processed showed general collapse. The material fixed in $1 \%$ or in $2 \%$ osmium tetro- 
xide in acetate-veronal buffer revealed no appreciable distorsion during preparation when observed under the light microscope but the same material when viewed under the electron microscope showed accentuate striation of the surface coat and insufficient intracellular detail with the exception of heavily deflecting areas in the vicinity of the plasmalemma. Isosmotic fixation employing $2 \%$ osmium tetroxide in 0.25 sucrose solution at $\mathrm{pH} 8-9$ resulted in better fixation with less intracellular distortion even when viewed under high magnifications $(2500 \times)$; other molar solutions of sucrose caused shrinkage or swelling after about two hours which was readily visible even under the light microscope.

Material fixed in osmium tetroxide solutions and rinsed in water before dehydration showed less detail when viewed in the electron microscope. When fixation was followed immediately with $70 \%$ alcohol much more detail was noted. It may be assumed that the greater clarity was due to the residual deposition of oxidation products of osmium tetroxide, alcohol, and the tissue. Substantial support was given this aasumption after viewing material in which $70 \%$ alcohol was added directly to the fixing hairs during the last ten minutes of fixation.

\section{Discussion}

Recent fixation instruction for plant material suggests $2 \%$ osmium tetroxide (in water?) (Johansen, 1940) probably in deference to, or acceptance of the classical investigation on fixation by Strangeways and Canti (1928). Animal tissue has been fixed in varying percentages of osmium tetroxide in distilled water (Anderson, 1953; Bahr and Beerman, 1954; Gall, 1954); in different percentages in acetate-veronal buffer (Afzelius, 1955; DeRobertis, 1954 ; Kauts and DeMarsh, 1955; Palade, 1952; Sjostrand and Hanzon, 1954); and in isosmotic solutions employing different salt concentrations.

For staminate hairs the above three procedures represent several basic faults. In the first instance whereas staminate hair cells, in a side experiment, were osmotically undisturbed by distilled water after more than eight hours, the addition of osmium tetroxide to a $1-2 \%$ concentration elicited visible osmotic imbalance during the first hour. The cell had been fixed, perhaps, but the selective permeability of the plasmalemma had been altered resulting either in the collapse inward of the cytoplasm or the rupture outward of the cell wall. It may be remarked here that similar results were not obtained when the hairs were processed on slides beneath slightly raised cover slips.

The use of osmium tetroxide in acetate-veronal buffer is incorrect physically. The preponderance of sodium salts and other electrolytes in the surrounding medium creates osmotically a salt imbalance within the cells since osmium fixation is not instantaneous through an entire tissue section (Porter and Kallman, 1953). As molecular aggregations are revealed during electron microscopy the migration of intracellular salts through osmotic imbalance 
would not reveal true perspectives. It has been suggested (Whitfield, 1955) that the bacterial "mitoses" recently observed (DeLamater, 1951) might be artefacts of buffer fixation. Similar "mitotic" effects have been produced by supercooling (Whitfield, 1955) during which iotic displacement is known to occur.

Isosmotic fixation is a true approach, however, salts in isosmotic fixation would present difficulties similar to those obtained in buffered fixation.

There are other damages which may result in normal processing of staminate hairs. Damage may result mechanically in transferring hairs from one container to another with pipettes or other instruments. The cells do not resume normal shape after even the slightest pressure. In the event solutions are poured off the material and the next solution poured on, the least exposure of the hairs to air may result in instantaneous evaporation and collapse of the central vacuole.

Osmium tetroxide alone, in solution, does not fix all cellular components (Bahr, 1954; Bairati and Lehmann, 1954), rather there appears to be an affinity for lipoidal substances (Baker, 1954 ; Finean, 1954 ; Johansen, 1940; Porter and Kallman, 1953). Researchers rinsing in 70\% alcohol and subsequently with higher grades of alcohols are in actuality completing fixation and forming side compounds (Osmium trioxide, Osmium dioxide, or other low oxides (Gray, 1954), relatively insoluble residual oxidation products marking the location of specific molecular aggregations. In a sence the osmium tetroxide solution arrested metabolic function; the alcohol stabilized structure.

\section{Conclusions}

A $2 \%$ solution of osmium tetroxide in 0.25 molar sucrose solution between $\mathrm{pH} 8$ and 9 gave best fixation of staminate hairs with least distortion.

Alcohol is necessary following fixation in osmium tetroxide both for completing fixation and possible for the creation of certain oxidation products which aid in greater electron deflection hence greater viewing clarity.

\section{References}

Afzelius, B. A. 1955. The ultrastructure of the nuclear membrane of the sea urchin oocytes as studied with the electron microscope. Exp. Cell. Res. 8: 147-58.

Anderson, N. G. 1953. On the nuclear envelope. Science 117: 517-21.

Bahr, N. G. 1954. Osmium tetroxide and ruthenium tetroxide and their reactions with biologically important substances. Exp. Cell Res. 7: 457-79.

- and Beerman, W. 1954. The fine structure of the nuclear membrane in the larval salivary gland and midgut of Chironomus. Exp. Cell Res. 6: 519-22.

Bairati, A. and Lehmann, F. E. 1954. Partial disintegration of cytoplasmic structures of Amoeba proteus after fixation with osmium tetroxide. Experientia 10: 173-5.

Baker, J. R. 1954. A study of the osmium techniques for the golgi apparatus. Quart.J. Micros. Sci. 95: 383-8.

DeLamater, E. D. 1951. A new cytological basis for bacterial genetics. Cold Spring Harbor Symposia on Quantitative Biology 16: 381-411. 
DeRobertis, E. 1954. The nucleo-cytoplasmic relationship and the basophilic substance (ergastoplasm) of invertebrate nerve cells. J. Histochem. and Cytochem. 12: $341-5$.

Finean, J. B. 1954. The effects of osmium tetroxide fixation on the structure of myelin in sciatic nerve. Exp. Coll Res. 6: 283-92.

Gall, J. G. 1954. Observations on the nuclear membrane with the electron microscope. Exp. Cell Res. 7: 197-200.

Granick, S. and Porter, K. R. 1947. The structure of the spinach chloroplast as interpreted by the electron microscope. Am. J. Bot. 34: 545-50.

Gray, Peter. 1954. The Microtomists Formulary and Guide, Blakiston, N. Y.

Johansen, D. A. 1940. Plant microtechnique. McGraw-Hill Co., N. Y.

Kautz, J. and DeMarsh, Q. B. 1955. Fine structure of the nuclear membrane in cells from the chick embryo; on the nature of the so-called pores in the nuclear membrane. Exp. Cell. Res. 8: 394-6.

Newman, S. B., Borysko, E. and Swerdlow, M. 1949. Ultra-microtomy by by a new method. J. Res. Nall. Bur. Standards. 43: 183-99.

Palade, G. E. 1952. A study of fixation for electron microscopy. J. Exp. Med. 95: 285.

Porter, K. and Kallman, F. 1953. The properties and effects of osmium tetroxide as a tissue fixative with special reference to its use for electron microscopy. Exp. Cell Res. 4: 127-41.

Sjostrand, F. S. and Hanzon, V. 1954. Membrane structure of cytoplasm and mitochondria in exocrine cells of mouse pancreas as revealed by high resolution microscopy. Exp. Cell Res. 7: 393-414.

Steinman, E. 1952. An electron microscope study of the lammellar structure of chloroplasts. Exp. Cell Res. 3: 367-72.

Strangeways, T. S. P. and Canti, R. G. 1928. The living cell in vitro as shown by darkground illumination and the changes induced in such cells by fixing reagents. Quart. J. Micros. Sci, 71: 1.

Whitfield, J. J. 1955. Personal communication. Nat. Res. Council of Canada for Atomic Energy. Ontariok Canada.

Wolken, J. J. and Palade, G. E. 1952. Fine structure of chloroplasts in two flagellates. Nature 170: 114-15. 